\title{
The Study of Syntactic Errors in English Writing on Fossilization Theory
}

\author{
Yi Huang ${ }^{1}$ \\ ${ }^{1}$ Institution: An Yang Normal College, China \\ Correspondence: Yi Huang, Institution: An Yang Normal College, China
}

Received: December 7, 2017

Accepted: September 17, 2018

Online Published: September 18, 2018

doi:10.5430/elr.v7n3p26

URL: https://doi.org/10.5430/elr.v7n3p26

\begin{abstract}
SLA researchers have long been baffled why native-like attainment is rare among adult L2 learners. They have been contributing to approaching the conundrum through the lens of fossilization (Selinker, 1972). Fossilization has aroused more and more attentions at home and abroad since proposed. This thesis consists of major five chapters. The Introduction section mainly introduces the origin and significance of study and outlines the fossilization research achievements at home and abroad from different facets, in which many foreign researchers provide their theoretical basis for the language fossilization, especially for the double effect on foreign language writing, whereas the domestic researchers make a lot of empirical studies that explore the correlation between language fossilization and instruction at different levels. Based on the foregoing analysis, the last chapter puts forward two objective proposals about teaching strategies and classroom activities for high school teachers. On one hand, the English writing teaching approach should be distinguished from the colloquial speech teaching approach because L2 writing pertains to a more formal language output, and the correct output of language forms should not be overlooked when concerning that of language meaning. Only on the basis of the correct language forms, language meaning will be naturally closer to the target language.
\end{abstract}

Keywords: fossilization, syntactic errors, English writing

\section{Introduction}

Fossilization in SLA has aroused more and more attentions at home and abroad since proposed. In the foreign language learning of Chinese senior high schools, some language errors occur repeatedly made by students so that their writing skills and linguistic competence remain in a state of stagnation. This chapter mainly involves the three sections as follows: the origin and significance of study, literature review, research method and design.

\section{Literature Review}

Fossilization, proposed by Selinker in the 1970s, refers to a process occurring from time to time in which incorrect linguistic features become a permanent part of the way a learner speaks or writes in his target language. It is Larry Selinker that makes a remarkable contribution to the fossilization theory. Up to now, there are a few researchers who have provided their own theoretical views, but most of them still remain some refinement and extension based on Selinker. This chapter mainly explains the study of fossilization theory abroad and the fossilization research on English writing in China.

\subsection{The Study of Fossilization Theory}

The notion of fossilization dates back to the two linguists Weinreich (1953) and Nemser (1971), who talked about "permanent grammatical competence" or "permanent intermediate systems". The person who made the greatest contribution to this problem is Larry Selinker. He first proposed this concept in 1972. At that time some basic features on language fossilization were summarized. That is to say, it is possible for learners that "they will cease their interlanguage development before they reach target language norms (Saville-Troike, 2008)." Selinker made the point that fossilization, as an interlanguage output, was both a cognitive mechanism and a structural-behavioral phenomenon, who also identified the following five factors (over-generalization of L2 rules, L1 interference, transfer of training, L2 communication strategies, L2 inappropriate learning strategies), of which the most important one is L1 interference. Since 1972, Selinker has made several revisions and broaden the referential linguistic scope of fossilization. From "backsliding" to "cessation of learning", he initially estimated only 5\% people could successfully achieve native-like competence, but he soon changed his mind, who claimed that no adult could make it in all discourse domains. Larry Selinker made a remarkable contribution to the fossilization theory. Over the years, there 
were other researchers who put forward their own theoretical views, but most of them still remained some refinement and extension based on Selinker.

Based on the definition of Selinker, some researchers proposed a wide array of learner behaviors on fossilization. For instance, there is a quick sketch of approved behavioral reflexes_-backsliding (Ellis, 1985), stabilized errors (Schumann, 1978), cessation of learning (Odlin, 1993), random use of grammatical and ungrammatical structures (Schachter, 1996), or persistent difficulty (Hawkins, 2000), etc. Some of them are verified by empirical studies devoted to the subject matter of fossilization, whereas some are like putative speculations without any empirical basis. But it is admitted that learners' repeated stabilized errors in their language output can be regarded as the performance of fossilization in the context of SLA.

So far the major research achievements above have been generalized, albeit rather sketchily, origins, definitions, principal fossilization performances, causal variables. In the last place, the significance of foreign language instruction and its relationship to fossilization will be further delved. Unlike other issues that have been experiencing a long-term hot debate in the SLA research, the role of L2 instruction as a whole has gone to a large extent undisputed. That is to say, there is no doubt that instruction does matter in SLA. But, many researchers are on the whole rather prudent in favoring the positive effects of instruction. Long (1983), a strong advocate of instruction, stressed that instruction might make a positive difference for classroom L2 acquisition, for instance, "the benefits of instruction appear to be the strongest at beginning levels and in acquisition-poor environments (Han Zhaohong, 2008, p.127)". But his view provides little insight into how instruction has aided acquisition, for it gives no specific description of the teaching categories. Compared with Long's view, Norris and Ortega(2000) rigorously gauging the general effectiveness of instruction, who not only confirmed Long's finding, but also made significant headway in terms of identifying differential effectiveness by verifying two types of instruction: explicit instruction and implicit instruction. The former stresses "focus on forms" that language forms should be prior to content, while the later means "focus on form" that highlights language meaning rather than forms. A focal point of controversy thereby emerged: should instruction on earth focus on language forms or on language meaning? It was constantly debated by many researchers without consensus. Krashen (1982) proposed "comprehensible input" in his Input Hypothesis that weaken the value of explicit instruction in favor of implicit instruction, namely, if input is understood and enough of it in class, the necessary grammar will automatically shape. This assumption had a major influence on language teaching in the 1980s because of his avoidance of the explicit teaching of grammar in class, but suffered being severely criticized by many researchers, who confirmed the effectiveness of an explicit explanation of grammatical structure in foreign language classroom, especially for adults. Opposite to Krashen's view, Swain stressed that it was crucial for learners to notice gaps in the interlanguage and learner production should be increased in meaningful situation. Hence, he proposed Output Hypothesis (1993) that output production, e.g. writing, as a means, could "push learners beyond semantic processing to perform syntactic processing (Han Zhaohong, 2008, p. 133)".

In summary, instruction has its potential positive as well as negative impact on learning, so how to achieve language output in meaningful situation and how to maximize the quality of language input are worth to be further explored in the field of SLA.

\section{Fossilization Research on English Writing in China}

As is clear from the preceding review, this thesis would make an analysis based on the Selinker's definition on fossilization. On the basis of Critical Period Hypothesis and Contrast Analysis and Error Analysis, the majority of second language learners are predicted to fail to achieve native-speaker competence. Fossilization, as then conceptualized, suggests a two-tier phenomenon from cognitive level and empirical level. This chapter aims to provide a quick sketch of its biological foundation and cognitive psychological foundation, and then offer an in-depth view on some putative behavioral reflexes and causal variables of the fossilization.

The Chinese scholars have begun to research the language fossilization of SLA since the late 1990s. Large as the quantities of empirical studies are, little attempt has been made to construct theories of fossilization so far, or to integrate insights from current researches into theories of SLA. Therefore, short of validity, the domestic researches leave much space to improve in this field.

Through searching the articles published in core periodicals from 1998 to 2014 with the keyword "language fossilization" on CNKI, in view of the high quality and the strong credibility of core journals that deserve the pioneer of the academic frontier and the development direction of SLA, the classified statistics from the retrieved articles show as follows: 


\section{Cognitive Psychological Foundation: Contrast Analysis \& Error Analysis}

For the purpose of interpreting a wide array of learner behaviors of fossilization, the two theoretical foundation Contrastive Analysis (Robert Lado,1957) and Error Analysis (Pit Corder, 1967). First, the CA approach to the study of SLA focuses on predicting and explaining the similarities and differences on the surface forms between L1 and the target L2, which extends another assumption that there is transfer in learning. Odlin (1989) claimed that transfer refers to cross-linguistic influences in L2 learning, usually the interference of L1 on L2. When L1 structure or rule is used in L2 utterance and that use is appropriate or correct in the L2, that is positive transfer; when the use is inappropriate and considered an error, that is negative transfer. It highlights that the L2 learner errors should be attributable to L1 negative transfer or interference (in this thesis L1 positive transfer will not be mentioned).

Nevertheless, Contrastive Analysis is not totally scientific, for there is a major limitation of the approach that can not account for many learner errors, most of which can not always be validated by L1 interference, especially between Chinese and English. Therefore, Error Analysis established by Pit Corder in the 1960s seems more comprehensive. It is an approach that focuses on description and analysis of actual learner errors, rather than idealized linguistic system attributed to native speakers of L1 and L2 because errors are windows into the learners' mind, and it is significant to analyze interlanguage (or learner language) that is independent of L1 and L2. Ellis (1994) proposed the procedure for analyzing learner errors as follows:

(1) Collection of a sample of learner language

(2) Identification of errors

(3) Description of errors

(4) Explanation of errors

In the procedure Ellis (1994) holds the view. that accounting for why errors are made is the most important step for exploring the process of SLA. Thus, there are two categories of learner errors, that is interlingual errors (between languages) and intralingual errors( within language). Actually, interlingual errors is similar to "Chinglish" we have known because of L1 interference or negative transfer, whereas intralingual errors may be caused by incomplete learning on L2 grammar. Here is a sentence written by a Chinese high school student in his writing:

"The weather is been very hot in Beijing. There climate last week warm."

(1)

(2)

(3)

(1) Intralingual error: this is a representative grammar errors that the student use "is" with "been" instead of "has", which indicates that he has not mastered the English auxiliary verb system in grammar which never exist in Chinese.

(2) Interlingual error: the meaning the student want to express is that "Na li de qi hou hen wen nuan." It is obvious that "there climate" is a direct translation of the Chinese phrase which would be used in this context. This is typical interference of Chinese on English.

(3) Interlingual error: in Chinese the word "warm" can regarded as a verb itself, but in English additional verb corresponding to English "was" would be used before it.

\subsection{Fossilization Theory}

As a cognitive mechanism and performance-related notion, fossilization (Selinker, 1972) means that the majority of second language learners are predicted to fail to achieve native-speaker competence. In the researching process, Selinker made several revisions on its definition:

Fossilization is the process whereby the learner creates a cessation of interlanguage learning, thus stopping the interlanguage from developing, it is hypothesized, in a permanent way (Selinker, 1996,). 
4.2 A Category and Factors of Syntactic Fossilization Errors

\begin{tabular}{lll}
\hline Category & Syntactic Errors & Causal Variables \\
\hline & 1. Tense errors & \\
& 2. Voice errors & \\
& 3. Non-finite verb errors & \\
& 4. Subordinate Clause errors & Incomplete learning to \\
Intralingual & 5. Concord/agreement errors & target language \\
errors & 6. Special sentence structure errors & over-generalization \\
& 7. "It" structure errors & \\
8. "There be" structure errors & \\
9. Direct/indirect speech errors & \\
10. Negation structure errors & \\
\hline
\end{tabular}

\section{Research Procedures on Writing Syntactic Errors}

Based on quantitative text analyzing research and questionnaire survey approach, the statistics derive from the following two parts_ the English writing samples from the testees' recent exams and the designed sentence corrections, involving L2 different basic syntactic knowledge. The former aims to evaluate the students' performance in the authentic writing context, and the later can be accessible to overall estimating the testees' language fossilization performance and syntactic competence, and then find adequate methods to dispose of their weaknesses.

\subsection{Error Category and Statistics on Writing Samples}

\begin{tabular}{lll}
\hline $\begin{array}{l}\text { Category } \\
\text { Quantity \&Proportion }\end{array}$ & Quantity & Proportion(\%) \\
\hline Intralingual errors & & \\
& 18 & 20.0 \\
1. Tense errors & 16 & 17.8 \\
2. Voice errors & 17 & 18.9 \\
3. Non-finite verb errors & 11 & 12.2 \\
4. Subordinate clause errors & 14 & 15.6 \\
5. Concord/agreement errors & 8 & 13.3 \\
6. Special sentence structure errors & 0 & 0 \\
7. "It" structure errors & 6 & 10.0 \\
8. "There be" structure errors & 0 & 0 \\
9. Direct/ Indirect speech errors & 0 & 0 \\
10. Negation structure errors & 28 & 46.7 \\
Interlingual errors &
\end{tabular}


5.2 Sentence Correction Questionnaire Statistics

\begin{tabular}{|c|c|c|c|c|}
\hline Items & No. & Quantity & Correct Numbers & Correct Rate (\%) \\
\hline \multirow{2}{*}{ Tense } & 1 & 90 & 70 & 77.8 \\
\hline & 2 & 90 & 72 & 80.0 \\
\hline \multirow{2}{*}{ Voice } & 3 & 90 & 74 & 82.2 \\
\hline & 4 & 90 & 36 & 40.0 \\
\hline \multirow{2}{*}{ Non-finite verb } & 5 & 90 & 81 & 90.0 \\
\hline & 6 & 90 & 79 & 87.8 \\
\hline \multirow{2}{*}{ Subordinate clause } & 7 & 90 & 56 & 62.2 \\
\hline & 8 & 90 & 37 & 41.1 \\
\hline \multirow{2}{*}{ Concord/agreement } & 9 & 90 & 55 & 61.1 \\
\hline & 10 & 90 & 36 & 40.0 \\
\hline \multirow{2}{*}{ Special sentence structure } & 11 & 90 & 85 & 94.4 \\
\hline & 12 & 90 & 85 & 94.4 \\
\hline \multirow{2}{*}{ "It" structure } & 13 & 90 & 38 & 42.2 \\
\hline & 14 & 90 & 78 & 86.7 \\
\hline \multirow{2}{*}{ "There be" structure } & 15 & 90 & 27 & 30.0 \\
\hline & 16 & 90 & 51 & 56.7 \\
\hline \multirow{2}{*}{ Direct/ Indirect speech } & 17 & 90 & 63 & 70.0 \\
\hline & 18 & 90 & 54 & 60.0 \\
\hline \multirow{2}{*}{ Negation structure } & 19 & 90 & 67 & 74.4 \\
\hline & 20 & 90 & 45 & 50.0 \\
\hline \multirow{10}{*}{$\begin{array}{l}\text { Interlingual errors } \\
\text { (Redundancy, } \\
\text { Ambiguity, } \\
\text { expressions) }\end{array}$} & 21 & 90 & 42 & 46.7 \\
\hline & 22 & 90 & 4 & 4.4 \\
\hline & 23 & 90 & 36 & 40.0 \\
\hline & 24 & 90 & 6 & 6.7 \\
\hline & 25 & 90 & 37 & 41.1 \\
\hline & 26 & 90 & 2 & 2.2 \\
\hline & 27 & 90 & 15 & 16.7 \\
\hline & 28 & 90 & 3 & 3.3 \\
\hline & 29 & 90 & 13 & 14.4 \\
\hline & 30 & 90 & 18 & 20.0 \\
\hline
\end{tabular}

\section{Pedagogic Strategies on Defossilizing Writing}

The solution to relieving English syntactic fossilization is to consider learner errors as sources of insight into learning processes, classify and analyze them. According to the analysis of the former chapter, this chapter specifically proposed practical writing teaching and learning strategies and activities for the high school students, from the following three perspective: strengthening syntactic training, reducing Chinglish expressions with contrast, as well as overcoming negative interference and correcting learning strategies. At last, a teaching plan has been designed for reducing syntactic errors and improving the learners' writing competence. 


\subsection{Teaching Strategies and Activities on Defossilizing Writing}

Since the 1980s a variety of foreign language teaching approaches have been proposed and developed by many researchers, which can be categorized into two standpoints: "focus-on-forms" and "focus-on-form" (Han Zhaohong, 2008). The former means that the language form itself, e.g. grammar, should be highlighted by teachers through deductive teaching method, whereas the later focuses on the meaning of language, and it advocates inductive teaching method, e.g. the popular Communicative Teaching Approaches. In this thesis the former viewpoint should be highlighted because writing represents a formal language and the learners' writing competence fossilization might be basically caused by the misuse of specific language forms. So, the following teaching strategies will focus on it in this chapter.

\subsubsection{Strengthening Grammatical Training in Writing}

It is impossible for learners to complete a composition of high quality without accurate grammar. In the light of the referred problems in the last chapter, the first point is to strengthening grammatical training in writing, for the purpose of reducing grammatical errors (intralingual errors) and improving form fossilization. The following writing task has been designed for senior students of high school without uncommon words, but they are some errors on grammatical forms in the sample, including tense and voice error, non-finite verb error, subordinate clause error, concord error, special sentence structure error, "it" structure error, as well as "there be" structure error. Then, teachers can set limited time to instruct students to finish the writing task by finding and correcting these errors.

Title: Recently the World Healthy Organization has made a survey about how people spend their vacations? The result has been reported as follows. Please describe the chart and give some suggestions about healthy lifestyle according to the following information.

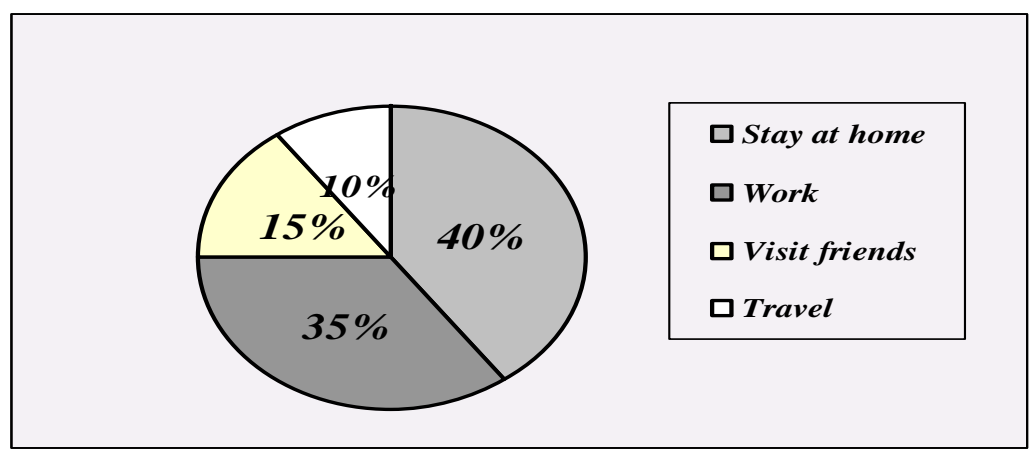

\section{Sample:}

In modern society, how do people spend their vacation? Recently the World Healthy Organization released $\rightarrow$ has released) a survey.

$\underline{\text { This }}(\rightarrow \mathbf{I t})$ is reported that most of people are fond of staying at home in their holidays. However, $\underline{i t}(\rightarrow$ there) is no doubt that some people have been ignored ( $\rightarrow$ have ignored) the importance of keeping healthy and good life habit because $35 \%$ of people prefer to work for earning money rather than resting $(\rightarrow$ rest) in their vacations. In addition, $15 \%$ of people want to visit friends for spending their vacations together. Only $10 \%$ of people choose to travel during their holidays.

It is high time that we develop ( $\rightarrow$ developed) a healthy lifestyle in our vacation. First, after a long time work, travel is absolutely of great importance to get us refreshed, which ( $\rightarrow$ by which) we can strengthen our body and mind. Also, visit ( $\rightarrow$ visiting) friends is a good way to keep healthy because regular social interactions can help us to relieve our working stress. Last but not least, reserving enough time to rest is beneficial to us. In a word, people who relax well would work well. Come and enjoy your vacation!

In this task teacher can firstly provide the original text, and then guide students to find all the syntactic errors and revise the text within a limited time. One of the advantages of the method is that it would not occupy too much time in one 45 minutes' class. Perhaps the teaching method proposed in this thesis is not the most effective for students, but it can be conducive to drawing the students' attention to basic grammar in writing and their syntactic form fossilization errors would be gradually lessened through the repeated stimulus-reinforcement training. 


\subsubsection{Overcoming Chinglish Expressions with Comparative Analysis}

This section mainly contributes to reducing learners' interlingual errors or Chinglish expressions caused by L1 interference. It can be assumed that overmuch L1 interference is attributable to the inappropriate learning strategies from students and low quality of input from teachers. Thus, the first gap requiring to be solved is the students' incorrect learning strategies. As mentioned above, avoidance is one of the major performance of students in their incorrect learning strategies. Kellerman (1977) differed three types of avoidance strategies: (1) the learners roughly acquires some L2 knowledge, not completely masters its rules, so he might avoid performing ambiguous and difficulty expressions in writing; (2) the learner find it difficult to use them in a certain SLA context even if he has mastered L2 rules; (3) the learner would be reluctant to use some expressions by the target language because of interlingual identification and emotional factors from L1 culture. It should be admitted that emotional cognition also deeply affect second language acquisition as one important subjective factor. Krashen (1982) proposed Affective Filter Hypothesis who pointed out the emotional state of the learners directly affects their learning behaviors and effectiveness, which means that positive emotion could be conducive to tackling more difficulties the learners encountered in learning, whereas negative emotions might impede the learners' potential development by avoidance. Therefore, the teachers should trigger students to build up learning interests as much as possible before the instruction of English writing skills. As instructing the syntactic knowledge, especially interpreting difficult points, the teachers should increase comprehensible input in class through the introduction about the differences of culture, thinking mode, or living habits, providing the writing topics close to daily lives, so as to help students to better understand the target language, and adapt to its expressing pattern, as well as overcome the emotional interference from native language. In addition, teachers should be cautious to avoid excessive reaction that might cause the stress and anxiety of students when correcting fossilization errors in writing tasks in case their learning confidence and positive emotions would be sapped. That is to say, it is inevitable that students make mistakes caused by L1 negative transfer in writing, but the teachers should hold a positive attitude and give students opportunities to introspect and revise because these phenomena suggest that the learners are experiencing a positive learning progress, who require to be given positive feedback and gradually approach ultimate L2 attainment with authentic English.

\section{Summary}

Language transfer in SLA originates from Contrastive Analysis theory which emerged in the 1940s and the 1950s. Incomplete L2 learning easily bring about negative transfer, which may cause the development of interlanguage forming a process of fossilization on speaking or writing. As a system of learner language which is at least partially independent of L1 and L2, interlanguage has been highly productive in the study of SLA. In the article the Significance of Learners' Errors (1967), S. Pit Corder claimed that accounting for why an error was made is the most important step in trying to understand the processes of SLA. Two of the most likely causes of L2 errors are interlingual (between languages) factors, resulting from negative transfer or interference from L1 and intralingual (within L2) factors, not attributable to cross-linguistic influence. This thesis mainly analyzes the performance of language fossilization in English writing from three perspectives, and how to apply Grammar-Translation Method into writing teaching, and give a proposal of translating activities for the purpose of improving senior high school students' writing skills.

\section{References}

Ellis, R. (1985). Understanding Second Language Acquisition. Oxford University Press.

Ellis,R. (1994). The Study of Second Language Acquisition. Oxford: Oxford University Press.

Hawkins,R. (2000). Persistent selective fossilization in second language acquisition and the optimal design of the language faculty. Essex Research Reports in Linguistics, 34, 75-90.

Han ZhaoHong. (2008). Fossilization in Adult Second Language Acquisiton. Peking: Foreign Language Teaching and Research Press.

Kellerman,E. (1997). Towards a characterization of the strategies of transfer in second language learning. Interlanguage Studies Bulletin 2, 58-145.

Krashen,S.D. (1982). Principles and Practice in Second Language Acquisition. Pergamon.

Long ,M. (1983). Does second language instruction make a difference? A review of the research. TESOL Quarterly, 17, 359-382. https://doi.org/10.2307/3586253

Nemser, W. (1971). Approximatetive Systems of Foreign Language Learner. IRAL, (2), 115-124.

Norris \& Ortega. (2000). Effectiveness of L2 instruction:A research synthesis and quatiative meta-analysis. 
Language Learning, 50, 417-528. https://doi.org/10.1111/0023-8333.00136

Odlin, T. (1989). Language Transfer: Cross-linguistic Influence in Language Learning. Cambridge: Cambridge University Press. https://doi.org/10.1017/CBO9781139524537

Robert Lado. (1957). Linguistics Across Cultures. University of Michigan Press.

S.Pit Corder. (1967). The significance of Learner's Errors.

Saville Troike. (1996). Introducing Second Language Acquisition, 2008. Schachter,Maturation and the issue of Universal Grammar in second language acquisition. In W. Ritchie and T. Bhatia(eds.), Handbook of second language acquisition. San Diego: Academic Press, 159-93.

Selinker, L. (1972). Interlanguage. International Review of Applied Linguistics in Language Teaching, 10, 209-232. https://doi.org/10.1515/iral.1972.10.1-4.209

Selinker L. (1996). Research proposal for grant application submitted to the British Library.

Weinreich, U. (1953). Languages in Contact.The Hague: Mouton. 